\title{
Factors controlling rock-clay buffer interaction in a radioactive waste repository
}

\author{
A. Gens*, L. do N. Guimaraes, A. Garcia-Molina, E.E. Alonso \\ Department of Geotechnical Engineering, Universitat Politècnica de Catalunya, DIT-ETS, Ingenieros de Caminos, \\ c/ Jordi Girona 1-3, 08034 Barcelona, Spain
}

Received 24 July 2000; accepted 15 January 2002

\begin{abstract}
The paper examines the interaction between host rock and a clay-based engineered barrier in the context of deep underground disposal of high-level radioactive waste. A large scale "in situ" heating test currently under way in the underground Grimsel Rock Laboratory (GRL; Switzerland) is adopted as a representative case for study. The main features of the behaviour of the rock/barrier system have been examined using a comprehensive programme of coupled thermo-hydromechanical analyses. A parametric study has been performed to assess the effects of individual phenomena and parameters. The characterisation activities carried out in relation with the in situ test provide the information on material properties and test conditions required. Results highlighting the influence of vapour diffusion, permeability, and retention curve of rock and bentonite are presented. The interaction between clay barrier and host medium exhibits a high degree of complexity. (C) 2002 Elsevier Science B.V. All rights reserved.
\end{abstract}

Keywords: Buffer; Rock; Clay; Thermo-hydro-mechanical analyses; Diffusion

\section{Introduction}

Deep geological disposal is, at present, one of the preferred alternatives for the safe disposal of highlevel radioactive waste. Crystalline rocks, clay-rich rocks, and salt have been considered as suitable host media in which a repository can be built. Waste would be placed in horizontal drifts or vertical boreholes excavated at large depths in an appropriate rock (Chapman and Mc Kinley, 1987).

The space between the canisters containing the waste and the excavation is to be backfilled with a

\footnotetext{
${ }^{*}$ Corresponding author. Fax: +34-93-401-7251.

E-mail address: Antonio.Gens@upc.es (A. Gens).
}

material selected in such a way that the backfill constitutes an engineered barrier with especially designed characteristics. In most envisaged designs, expansive clays have been chosen as the most adequate material on its own or in combination with other materials. In repositories built in rock salt, crushed salt is deemed to be preferable to a clay-based barrier.

The clay constituting the barrier is to be compacted to a high density to ensure sufficient swelling upon wetting. Selection of a clay with a high smectite content assists in giving the buffer material the required expansive properties. Therefore, the clay-rich barrier surrounding the waste will be a low permeability, high-density material that, at least initially, will be in an unsaturated state. In the course of time, the barrier will be subjected to thermal loading from the 
heat generated by the radioactive waste and to hydration from water drawn from the surrounding rock.

To ensure the long-term safety of the isolation system, it is necessary to understand the interaction between host rock and engineered barrier. Various thermal, hydraulic, and mechanical effects occur that interact with each other in a coupled manner (Gens et al., 1998). The intricacy of the interaction of the various phenomena involved and the widely different properties of barrier and host medium lead to a highly complex situation that requires careful examination.

The number of variables in the problem is so large, however, that it is not realistic to study the problem in all its generality. It is necessary to focus in a particular instance, preferably of practical interest. In this respect, large-scale tests reproducing repository conditions are especially useful as they provide intensely instrumented full-scale models of actual conditions. Those tests also supply specific cases in which the effects of various parameters and processes can be investigated in situations that have practical relevance.

ENRESA, the Spanish Agency for radioactive waste disposal, is carrying out one such full-scale test, FEBEX, in the underground Rock Laboratory in Grimsel (Switzerland). This "in situ" test will be used as the basic case for exploring the interaction between host medium and clay barrier. In the paper, the coupled thermo-hydro-mechanical (THM) formulation used to carry out the analyses is presented first. Afterwards, a description of the test and the properties of the materials involved is followed by the discussion of results selected from a comprehensive set of parametric studies carried out in relation with the design and interpretation of the test. Those results highlight important features of the thermo-hydro-mechanical behaviour of the barrier/host rock system.

\section{Formulation}

The coupled THM formulation required to carry out the analyses has been presented elsewhere (Olivella et al., 1994; Gens et al., 1998). However, for completeness, a brief description is given here. The formulation is based on a multiphase, multispecies approach (Panday and Corapcioglu, 1989). It is assumed that the porous medium is composed of three species: mineral, water, and air, distributed in three phases: solid, liquid, and gas. The liquid phase contains water and dissolved air and the gas phase contains dry air and water vapour.

The formulation takes into account the basic thermal, hydraulic, and mechanical phenomena that are relevant to the coupled analysis in porous materials. Specifically, the following ones have been explicitly incorporated:

\begin{tabular}{ll}
\hline Heat transport & $\begin{array}{l}\text { Heat conduction } \\
\text { Heat advection (liquid water) } \\
\text { Heat advection (water vapour) }\end{array}$ \\
& $\begin{array}{l}\text { Heat advection (gaseous air) } \\
\text { Phase changes } \\
\text { Liquid phase } \\
\text { Water vapour diffusion } \\
\text { Water flow }\end{array}$ \\
Gir flow & $\begin{array}{l}\text { Dissolved air diffusion } \\
\text { Behaviour of porous material } \\
\text { dependent on stresses, suction, } \\
\text { and temperature }\end{array}$ \\
\hline
\end{tabular}

The following assumptions are made in the formulation of the problem.

- Dry air is considered a single species and usually, it is the main component of the gaseous phase.

- Thermal equilibrium between phases is assumed. This means that the three phases are at the same temperature.

- Balance of momentum for the medium as a whole is reduced to the equation of stress equilibrium together with a mechanical constitutive model to relate stresses with strains. Strains are defined in terms of displacements.

- Small strains and small strain rates are assumed for solid deformation. Advective terms due to solid displacement are neglected after the formulation is transformed in terms of material derivatives (in fact, material derivatives are approximated as Eulerian time derivatives). In this way, volumetric strain is properly considered.

- Physical parameters in constitutive laws are function of pressures and temperature.

The equations that govern this problem can be categorized into three main groups: balance equations, constitutive equations, and equilibrium relationships. 
The balance equations establish the conditions for water mass conservation, air mass conservation, energy conservation, and momentum conservation (equilibrium). They are solved simultaneously to take into account, in a proper manner, the various couplings between phenomena. The unknowns (state variables) are liquid pressure, gas pressure, temperature, and displacements.

The constitutive equations establish the link between the state variables (or unknowns) and the dependent variables. There are several categories of dependent variables depending on the complexity with which they are related to the unknowns. The governing equations are finally written in terms of the unknowns when the constitutive equations are substituted in the balance equations.

Another type of relationships that relates dependent variables with unknowns are the equilibrium restrictions. They are obtained assuming chemical equilibrium for dissolution of the different species (air and vapour) in phases (liquid, gas). This assumption is sufficiently adequate because these chemical processes are fast compared to the transport processes that take place in this type of porous media and, therefore, they are not rate controlling.

Constitutive equations and equilibrium restrictions are summarized in Table 1. The following points should be noted:

- Fourier's law: thermal conductivity depends on the porosity and state of hydration of the material through a modified geometric mean expression;

- Specific heat: the specific heat is considered additive with respect to the various components of a porous medium;

- Darcy's law: hydraulic conductivity depends on porosity, degree of saturation, and, via water viscosity, on temperature;

- Retention curve: a relationship between degree of saturation and suction including hysteresis is adopted.

- Fick's law for vapour diffusion: a tortuosity coefficient, $\tau$, is included to take into account the effect of diffusion in a porous medium;

- The mechanical constitutive law explicitly considers the effects of strains, suction, and temperature changes.
The formulation has been discretized using Galerkin's approach for space discretization and finite differences for time discretization. A computer code, CODE_BRIGHT (Olivella et al., 1996) has been developed to perform coupled THM analyses in two and three dimensions. The full Newton Raphson method is used to solve the resulting nonlinear set of algebraic equations.

\section{The FEBEX in situ test}

The FEBEX in situ test is a large-scale heating test that is being carried out at the Grimsel Rock Laboratory (GRL) in the Swiss Alps. The test tries to reproduce the main features of the current Spanish concept for deep underground disposal of high-level radioactive waste (ENRESA, 2000).

The test layout (Fig. 1) consists of placing two heaters at the end of a drift which is $2.28-\mathrm{m}$ diameter and 70.4-m length especially bored for this purpose. The diameter and length of the heaters (0.9 and 4.54 $\mathrm{m}$, respectively) corresponds to the actual dimensions of the canister envisaged for radioactive waste storage. The heaters are placed in the axis of the drift at a $1-\mathrm{m}$ distance from each other.

The space between the drift and the heaters is filled by blocks of compacted bentonite with a smectite content in the range of $88-96 \%$. Mean value of initial dry density and water content are $1.7 \mathrm{~g} / \mathrm{cm}^{2}$ and $14.4 \%$, leading to an initial degree of saturation of about $65 \%$.

The host rock is a good quality Central Aare granite crossed, in the test zone, by a lamprophyre dyke. The 17-m-long test zone at the end of the drift is sealed by a concrete plug. The test is heavily instrumented. The monitoring system includes the measurement of temperatures, relative humidity (total suction), pore pressures, displacement, and stresses.

The test schedule involves switching on the heaters at a prescribed power until the temperature reaches a value of $100{ }^{\circ} \mathrm{C}$ at some point in the bentonite. From that moment on, the power of the heaters is constantly adjusted in order to keep the maximum temperature in the bentonite barrier at the $100{ }^{\circ} \mathrm{C}$ mark. It is planned that heating will be applied for more than 3 years. At the end of the heating period, the heaters will be switched off and a cooling period will ensue. Once the 
Table 1

Summary of constitutive laws and equilibrium restrictions

\begin{tabular}{|c|c|c|c|}
\hline Equation & Variable name & Equation & Parameter relationships \\
\hline $\begin{array}{l}\text { Constitutive equo } \\
\text { Darcy's law }\end{array}$ & $\begin{array}{l}\text { liquid and gas } \\
\text { advective flux }\end{array}$ & $\begin{aligned} \mathbf{q}_{\alpha} & =-\frac{\mathbf{k} k_{\mathrm{r} \alpha}}{\mu_{\alpha}}\left(\nabla P_{\alpha}-\rho_{\alpha} \mathbf{g}\right) \\
\alpha & =1, g\end{aligned}$ & $\begin{array}{l}\mathbf{k}=\mathbf{k}_{0} \frac{\phi^{3}}{(1-\phi)^{2}} \frac{\left(1-\phi_{0}\right)^{2}}{\phi_{0}^{3}} \\
k_{\mathrm{rl}}=S_{\mathrm{e}}^{1 / 2}\left(1-\left(1-S_{\mathrm{e}}^{1 / \beta}\right)^{\beta}\right)^{2} \\
k_{\mathrm{rg}}=1-k_{\mathrm{rl}}\end{array}$ \\
\hline Fick's law & $\begin{array}{l}\text { Vapour non } \\
\text { advective flux }\end{array}$ & $\begin{aligned} i_{\mathrm{g}}^{\mathrm{w}} & =-\mathbf{D}_{\mathrm{g}}^{\mathrm{w}} \nabla \omega_{\mathrm{g}}^{\mathrm{w}} \\
& =-\left(\phi \rho_{\mathrm{g}} S_{\mathrm{g}} \tau D_{\mathrm{m}}^{\mathrm{w}} \mathbf{I}\right) \nabla \omega_{\mathrm{g}}^{\mathrm{w}}\end{aligned}$ & $D_{\mathrm{m}}^{\mathrm{w}}\left(\mathrm{m}^{2} / \mathrm{s}\right)=5.9 \times 10^{-12} \frac{(273.15+T)^{2.3}}{P_{\mathrm{g}}}$ \\
\hline Fourier's law & $\begin{array}{l}\text { conductive } \\
\text { heat flux }\end{array}$ & $\boldsymbol{i}_{c}=-\lambda \nabla T$ & $\lambda=\lambda_{\mathrm{s}}^{S_{1}^{n}} \lambda_{\mathrm{d}}^{\left(1-S_{\mathrm{l}}\right)^{1 / n}}$ \\
\hline Retention curve & $\begin{array}{l}\text { liquid phase } \\
\text { degree of } \\
\text { saturation }\end{array}$ & $S_{\mathrm{e}}=\left(1+\left(\frac{s}{P_{0}}\right)^{\frac{1}{1-\beta}}\right)^{-\beta}$ & $\begin{array}{l}S_{\mathrm{e}}=\frac{S_{1}-S_{\mathrm{lr}}}{S_{\mathrm{ls}}-S_{\mathrm{lr}}} \\
S_{\mathrm{g}}=1-S_{\mathrm{l}}\end{array}$ \\
\hline Phase density & $\begin{array}{l}\text { liquid density, } \\
\text { gas density }\end{array}$ & $\begin{array}{l}\rho_{1}=\rho_{10} \mathrm{e}^{\beta\left(P_{1}-P_{\mathrm{lo}}\right)+\alpha T} \\
\rho_{\mathrm{g}}: \text { ideal gas law }\end{array}$ & \\
\hline Phase viscosity & $\begin{array}{l}\text { liquid viscosity, } \\
\text { gas viscosity }\end{array}$ & $\begin{array}{l}\mu_{1}(\mathrm{MPa} \mathrm{s})=2.1 \times 10^{-12} \mathrm{e}^{\left(\frac{1808.5}{273.15+T}\right)}, \\
\mu_{\mathrm{g}}(\mathrm{MPa} \mathrm{s})=\frac{1.48 \times 10^{-12} \sqrt{273+T}}{\left(1+\frac{119.4}{273+T}\right)}\end{array}$ & \\
\hline $\begin{array}{l}\text { Mechanical } \\
\text { constitutive } \\
\text { model }\end{array}$ & stress tensor & $\begin{aligned} \mathrm{d} \sigma= & \mathbf{D} \mathrm{d} \varepsilon+\mathbf{h} \mathrm{d} s+\beta \mathrm{d} T \\
\mathbf{D}= & \left(\mathbf{C}^{\mathrm{ep}}+\mathbf{C}^{\mathrm{c}}\right)^{-1} \\
& (\text { elastoplasticity }+ \text { creep })\end{aligned}$ & \\
\hline $\begin{array}{l}\text { Equilibrium restr } \\
\text { Henry's law }\end{array}$ & $\begin{array}{l}\text { air dissolved } \\
\text { mass fraction }\end{array}$ & $\omega_{1}^{\mathrm{a}}=\frac{P_{\mathrm{a}}}{H} \frac{M_{\mathrm{w}}}{M_{\mathrm{a}}}$ & \\
\hline $\begin{array}{l}\text { Psychrometric } \\
\text { law }\end{array}$ & $\begin{array}{l}\text { vapour mass } \\
\text { fraction } \\
\text { (vapour pressure) }\end{array}$ & $p_{\mathrm{v}}=p_{\mathrm{v}}^{0} \mathrm{e}^{\left(\frac{-\left(P_{\mathrm{g}}-P_{1}\right) M_{\mathrm{w}}}{R(273+T) \rho_{1}}\right)}$ & $p_{\mathrm{v}}^{0}(\mathrm{MPa})=136,075 \mathrm{e}^{\left(\frac{-5239.7}{273+T}\right)}$ \\
\hline
\end{tabular}

temperature has dropped to an adequate level, the test will be dismantled to provide direct observations on the final state of the barrier.
The thermo-hydro-mechanical properties of the compacted bentonite and of the rock have been determined by means of a comprehensive character- 
isation programme including laboratory and in situ tests. Fig. 2 shows the very low intrinsic permeability value of the bentonite and its dependency with porosity. The retention (characteristic) curve linking suction and degree of saturation is presented in Fig. 3 where drying and wetting curves are distinguished. The permeability of the rock (including the contribution of discontinuities) is significantly higher, of the order of $8 \times 10^{-18} \mathrm{~m}^{2}$. Even the mass permeability of the granite, $10^{-18} \mathrm{~m}^{2}$, is higher than that of the bentonite. The retention curve for the granite, as determined in the laboratory, is shown in Fig. 4. It is interesting that the granite appears to have a rather low air entry value, certainly lower than that of the bentonite.
The thermal parameters, the mechanical properties, and the rest of the hydraulic relationships are described in Gens et al. (1997) and are not given here for reasons of space.

\section{Interaction clay barrier-host rock}

\subsection{General}

The FEBEX in situ experiment has been the object of an intensive numerical modelling exercise in order to assist in the design and interpretation of the test. Coupled thermo-hydro-mechanical fi-
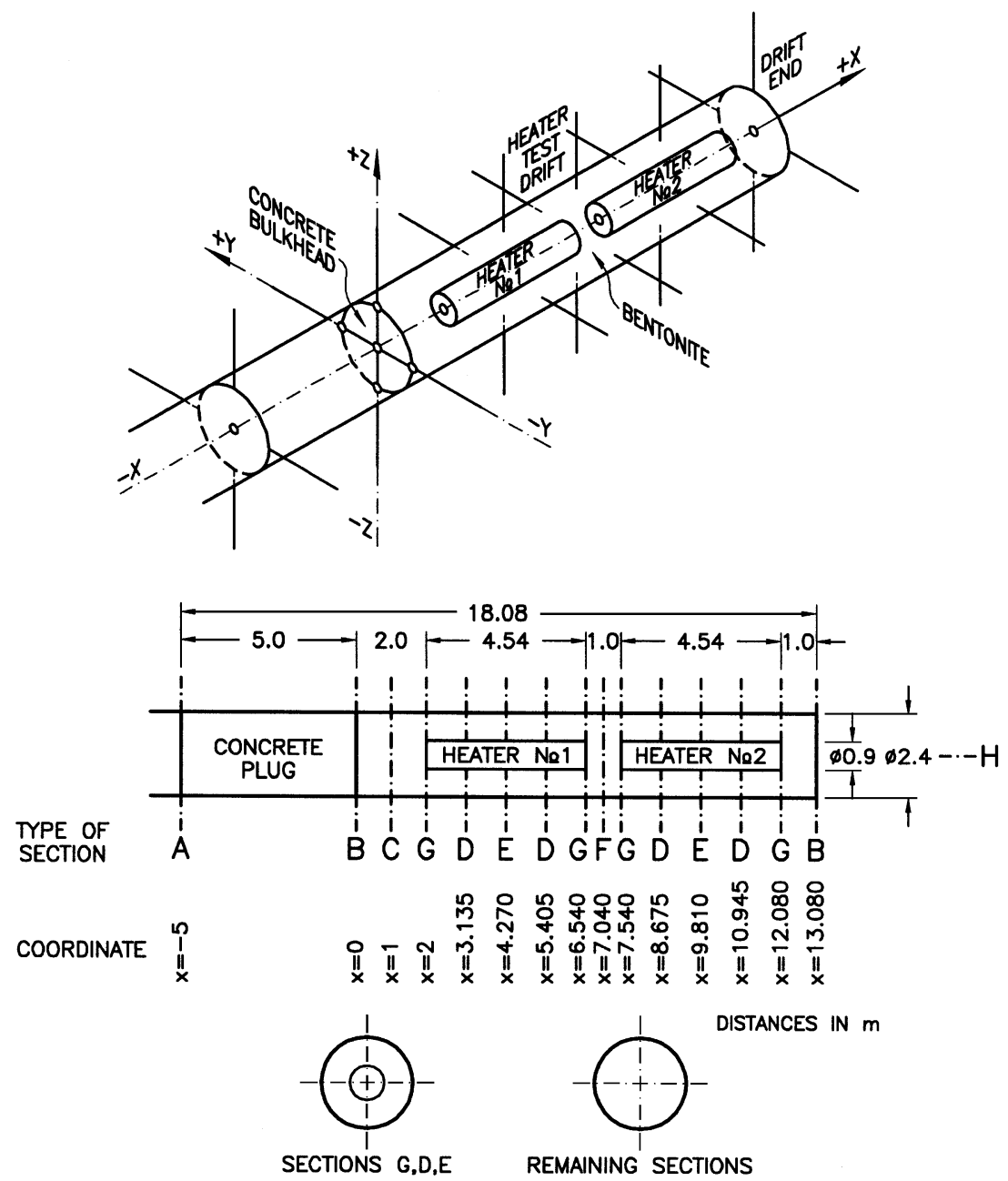

Fig. 1. Layout of the test. 


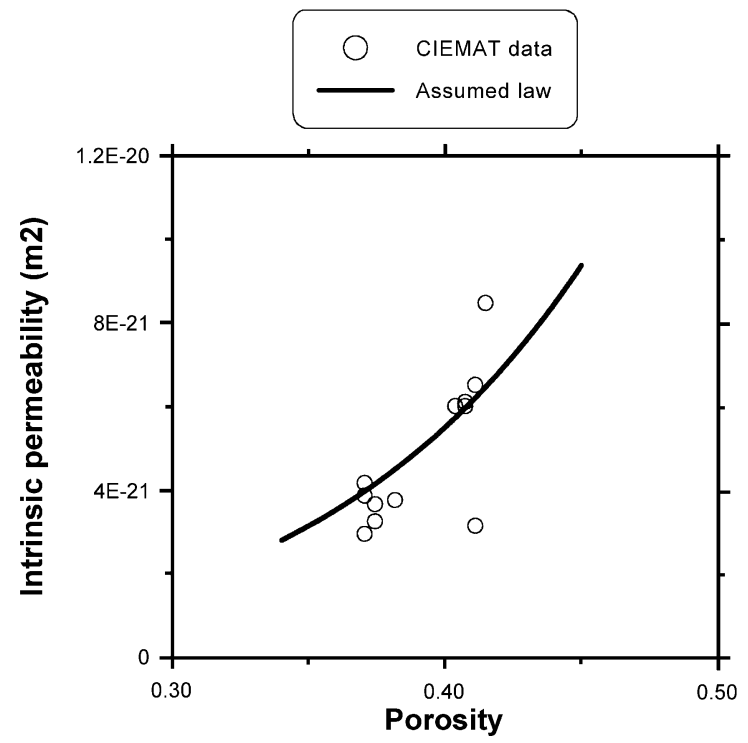

Fig. 2. Variation of the intrinsic permeability of the bentonite with porosity. Experimental results (Villar and Pelayo, 1996) and relationship adopted in the analysis.

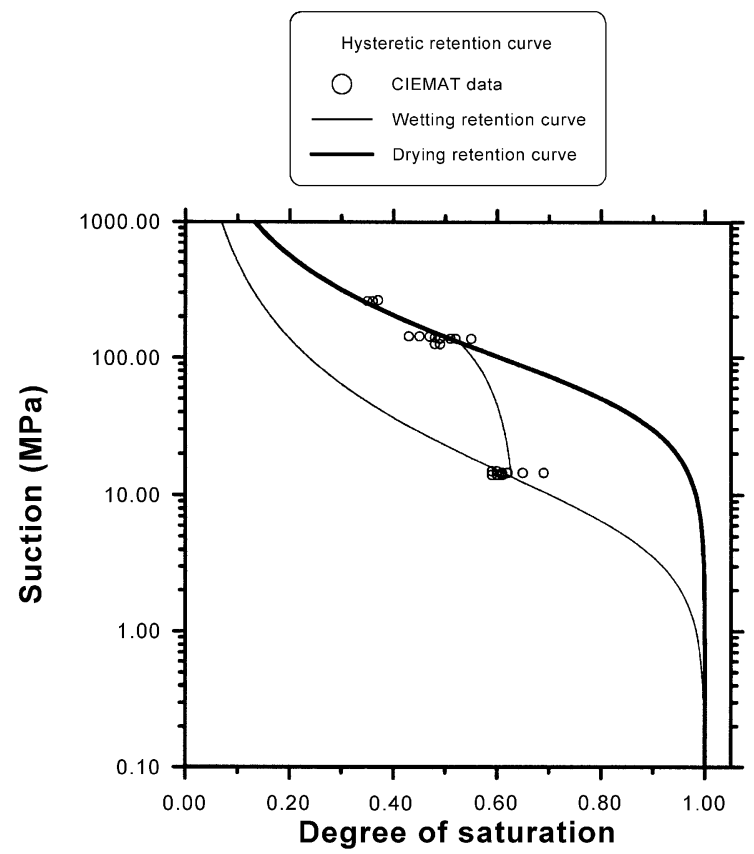

Fig. 3. Bentonite retention curves. Experimental results from Villar and Pelayo (1996).

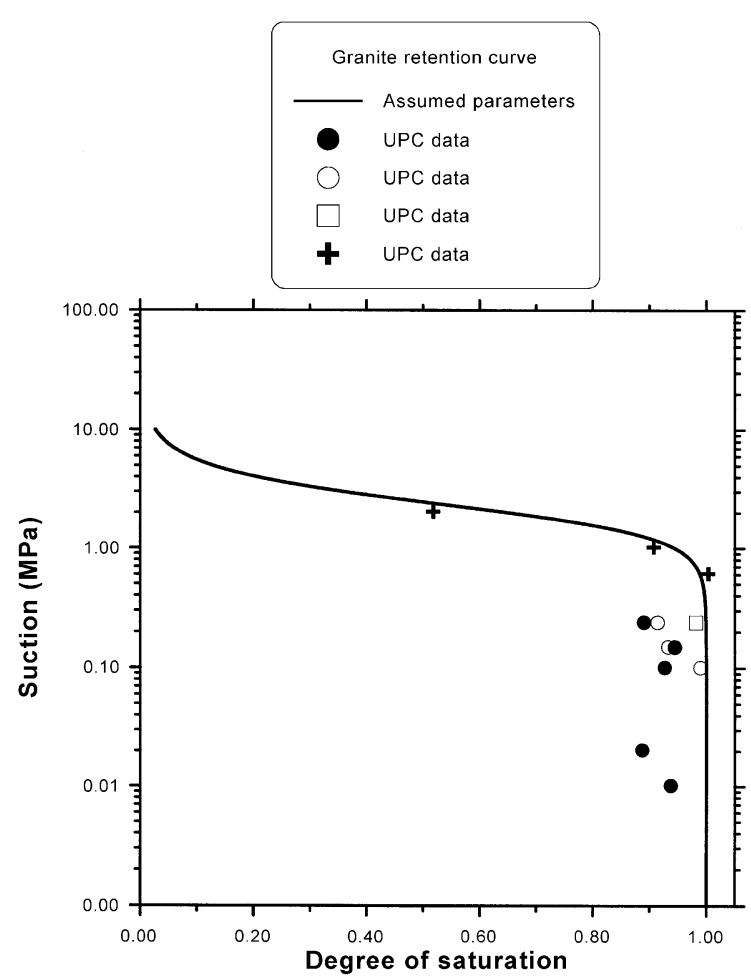

Fig. 4. Retention curve adopted for the granite. Experimental results from Pintado and Lloret (1996).

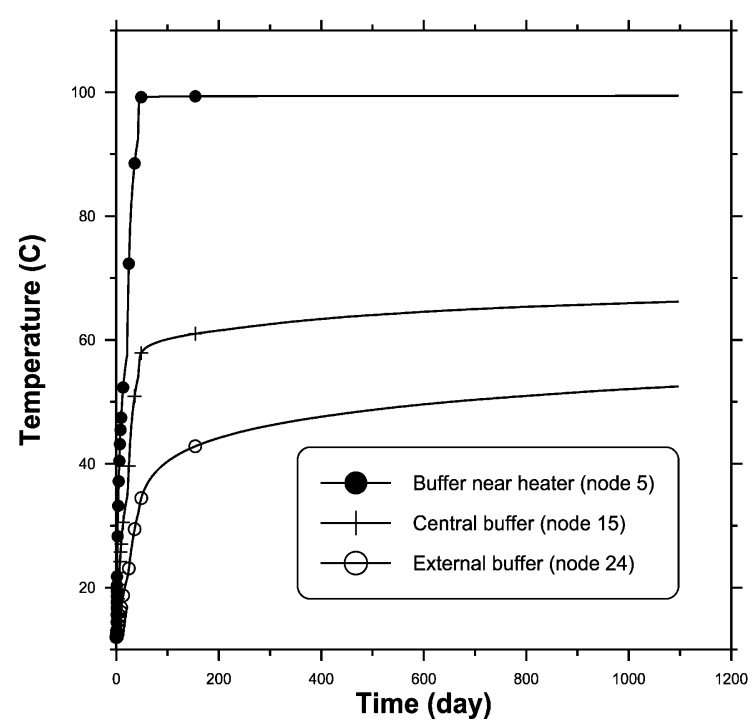

Fig. 5. Variation of temperature with time. Base Case analysis. 
nite element analyses using the computer simulator CODE_BRIGHT have been carried out in order to account for all the significant phenomena occurring in the barrier and adjacent rock.

As part of the numerical modelling programme, parametric analyses have been performed to check the effect of individual parameters and processes on the overall behaviour of the barrier. This parametric study provides important information in a number of aspects of the interaction of the host geological medium with the clay barrier. For brevity, only the effect of a limited number of parameters (vapour diffusion, permeability, relation curves) will be presented herein.

\subsection{Features of the analyses}

The analyses has been carried out using a 1-D geometry with radial symmetry. Initial conditions, boundary conditions, and constitutive law parameters have been derived from an extensive field and laboratory-testing programme carried out before the performance of the test. According to the hydrogeological investigations, the water flow close to the tunnel is mainly radial tending gradually towards the regional flow direction over a distance of $50 \mathrm{~m}$. Accordingly, the outer domain boundary has been fixed at a radial

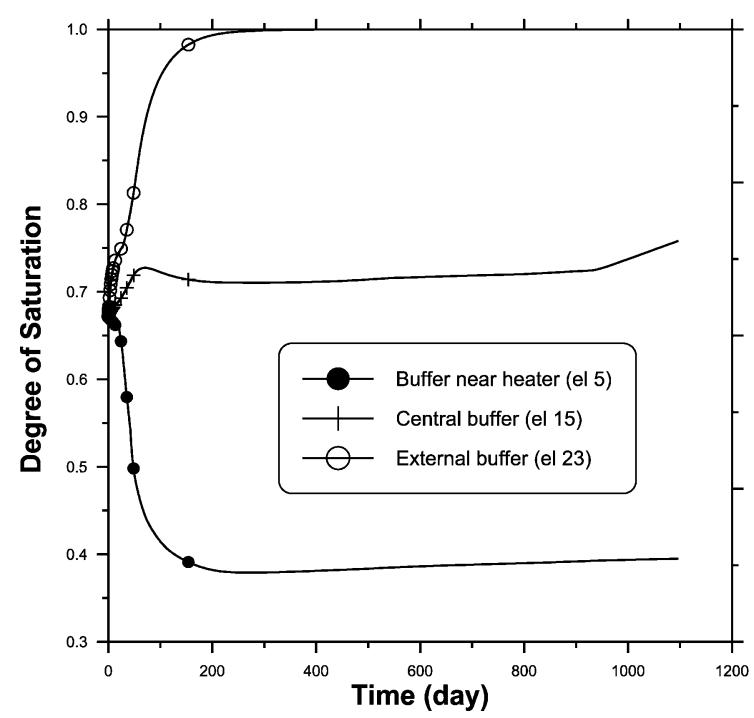

Fig. 6. Variation of degree of saturation with time. Base Case analysis.

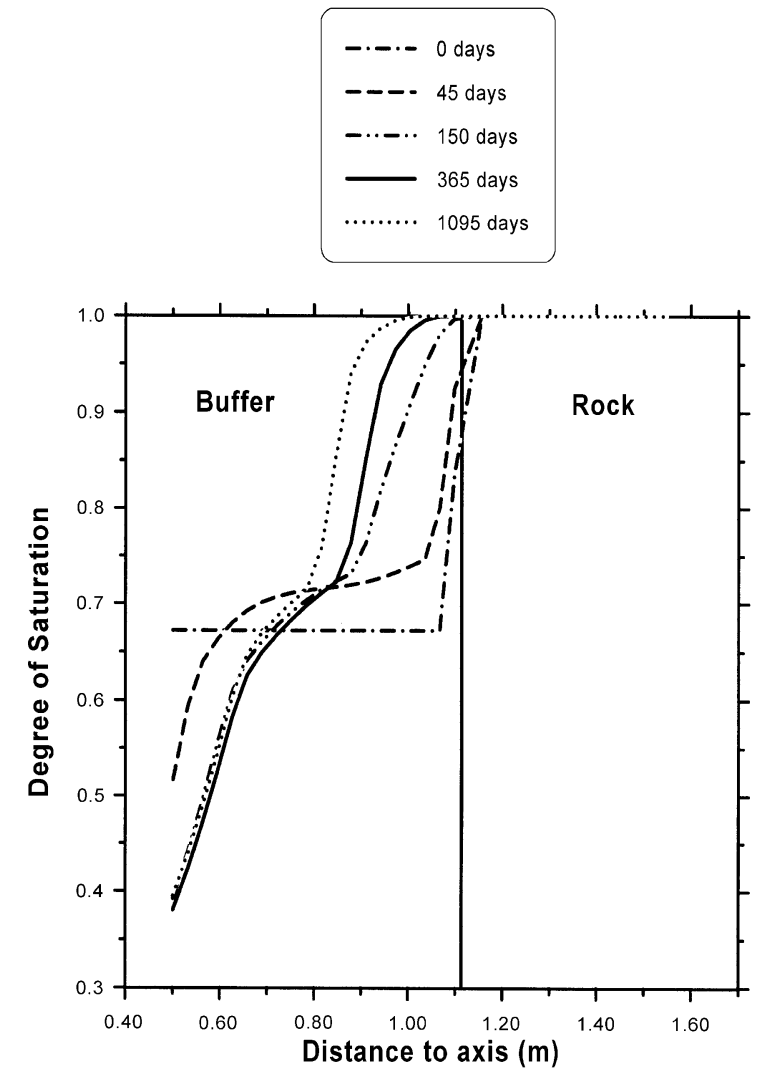

Fig. 7. Distributions of degree of saturation at various times. Base Case analysis.

distance of $50 \mathrm{~m}$ where a water pressure of $0.7 \mathrm{MPa}$ (typical of the values measured before tunnel excavation) has been prescribed.

The thermal and mechanical boundary condition prescribed at $r=50 \mathrm{~m}$ are:

- Temperature, $T=12^{\circ}$;

- Radial stress, $\sigma_{\mathrm{r}}=28 \mathrm{MPa}$.

The thermal boundary conditions applied at the heater location $(r=0.385 \mathrm{~m})$ are:

$0-21$ days

Constant power: $1200 \mathrm{~W} /$ heater

21-42 days Constant power: $2000 \mathrm{~W} /$ heater 42 days $-t_{100}$ Constant power: $2400 \mathrm{~W} /$ heater $t_{100}-3$ years Constant temperature: $T=100{ }^{\circ} \mathrm{C}$ 
where $t_{100}$ is the time required to reach $100{ }^{\circ} \mathrm{C}$ at some point in the bentonite. Those conditions reproduce the planned heating schedule.

The analyses performed start simulating the excavation of the tunnel, allowing afterwards sufficient time for equilibration, both hydraulic and mechanical. Regarding mechanical variables, an initially uniform and isotropic stress field $\left(\sigma_{\mathrm{r}}=\sigma_{\theta}=\sigma_{\mathrm{z}}=28 \mathrm{MPa}\right)$ has been assumed. Initial granite porosity is taken as 0.01 .

As indicated above, the initial water content of the bentonite is $14.4 \%$, this corresponds to a degree of saturation of 0.66 and, from the retention curve adopted, an initial value of suction of $84 \mathrm{MPa}$. Initial stress is assumed isotropic and equals to $0.5 \mathrm{MPa}$ in the bentonite. Finally, a uniform initial temperature of $12{ }^{\circ} \mathrm{C}$ has been adopted throughout the domain. The mechanical behaviour of the bentonite has been modelled by a thermoplastic constitutive model specifically developed for unsaturated materials (Gens, 1995). For the host rock, a simple linear elastic model has been deemed acceptable.

The results will be given for three representative points in the engineered barrier: one near the heater (node 5 and element 5), a second one in the central part of the buffer (node 15 and element 15), and a third one near the rock (node 24 and element 23).

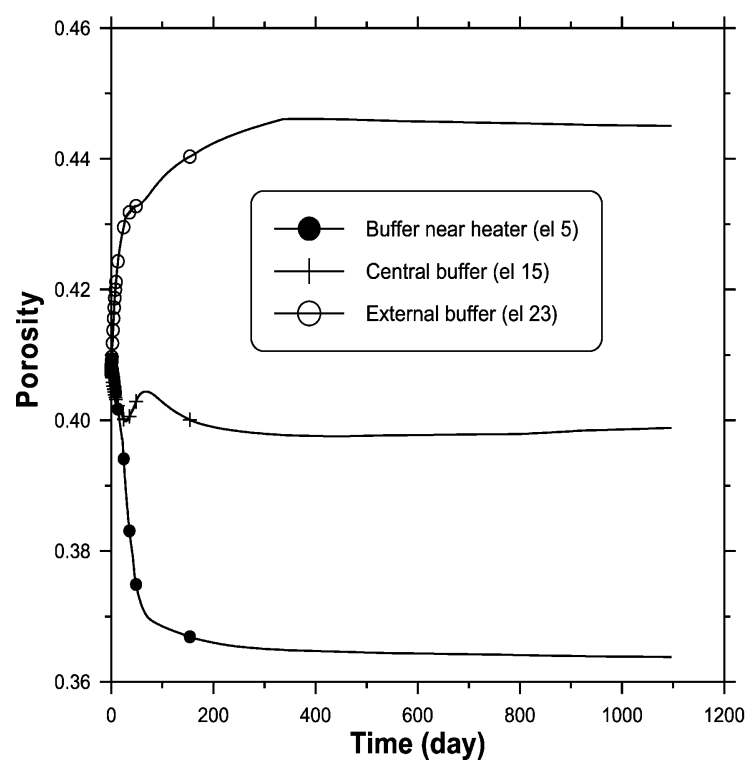

Fig. 8. Variation of porosity with time. Base Case analysis.

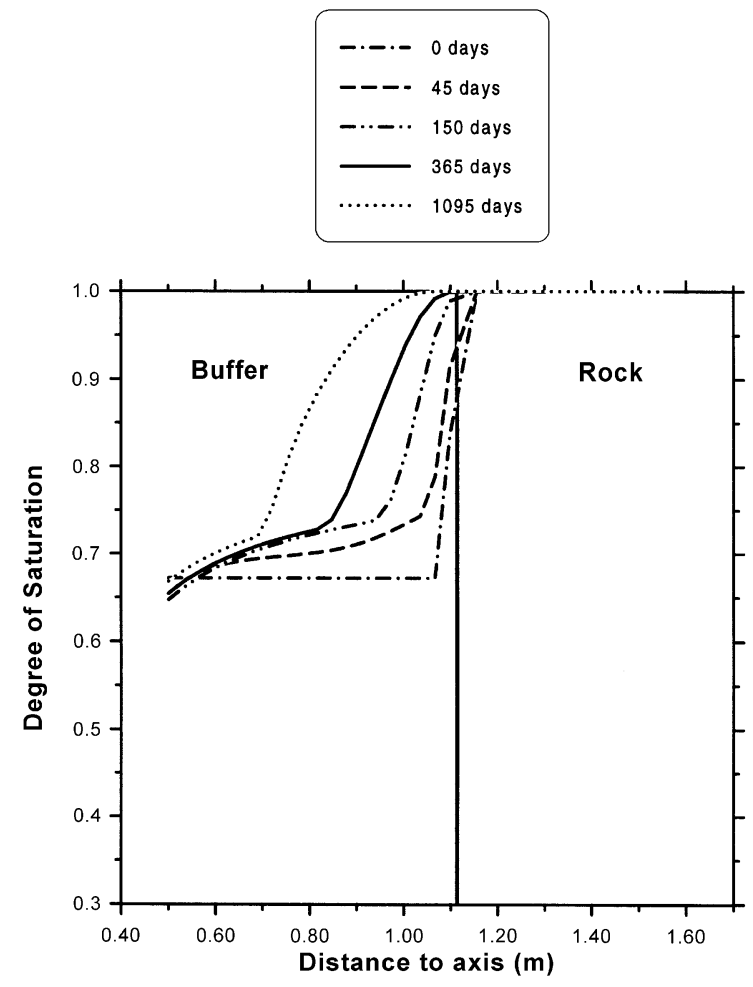

Fig. 9. Distribution of degree of saturation at various times. TB analysis (reduced vapour diffusion).

\subsection{Base Case results}

The Base Case analysis has been carried out using the best estimation of test conditions and parameters available at the time of performing the analyses as discussed in Gens et al. (1998). It provides the basic pattern of behaviour against which the results of the parametric studies are compared. The analyses have been extended over 3 years of the heating stage. Examples of the results obtained are presented in Figs. 5-8. The following points can be noted.

- The temperature increases quickly throughout the barrier until reaching a value of $100{ }^{\circ} \mathrm{C}$ close to the heater. It rises slowly afterwards, reflecting the change in thermal boundary condition (Fig. 5).

- The bentonite near the heater dries, whereas the degree of saturation increases close to the rock. The barrier as a whole is far from saturation at the end of 3 years (Figs. 6 and 7). 
- Practically no rock desaturation occurs with the parameters selected for the Base Case (Fig. 7).

- The bentonite near the heater contracts due to drying, whereas the material near the rock swells due to wetting (Fig. 8).

\subsection{Vapour diffusion}

In the analysis coded TB, the vapour diffusion velocity is diminished by an order of magnitude. As Fig. 9 shows, the effect of a reduced vapour diffusion rate is particularly noticeable near the heater. It can be noted that the dynamic equilibrium between the inflow of liquid water coming from the outer buffer areas and the vapour outflow is established at a much higher degree of saturation value. As a consequence, the pattern of porosity variation is also significantly affected with little drying occurring in the inner part of the barrier (Fig. 10). Vapour diffusion rate, therefore,

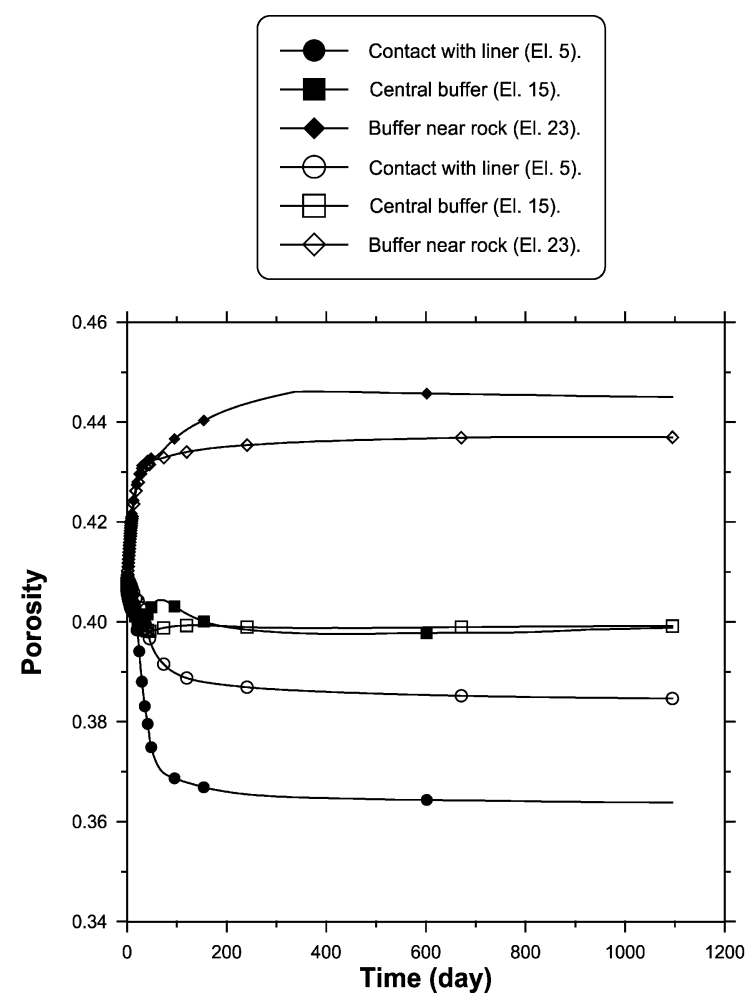

Fig. 10. Variation of degree of saturation with time. TB analysis (reduced vapour diffusion). Black symbols correspond to Base Case.

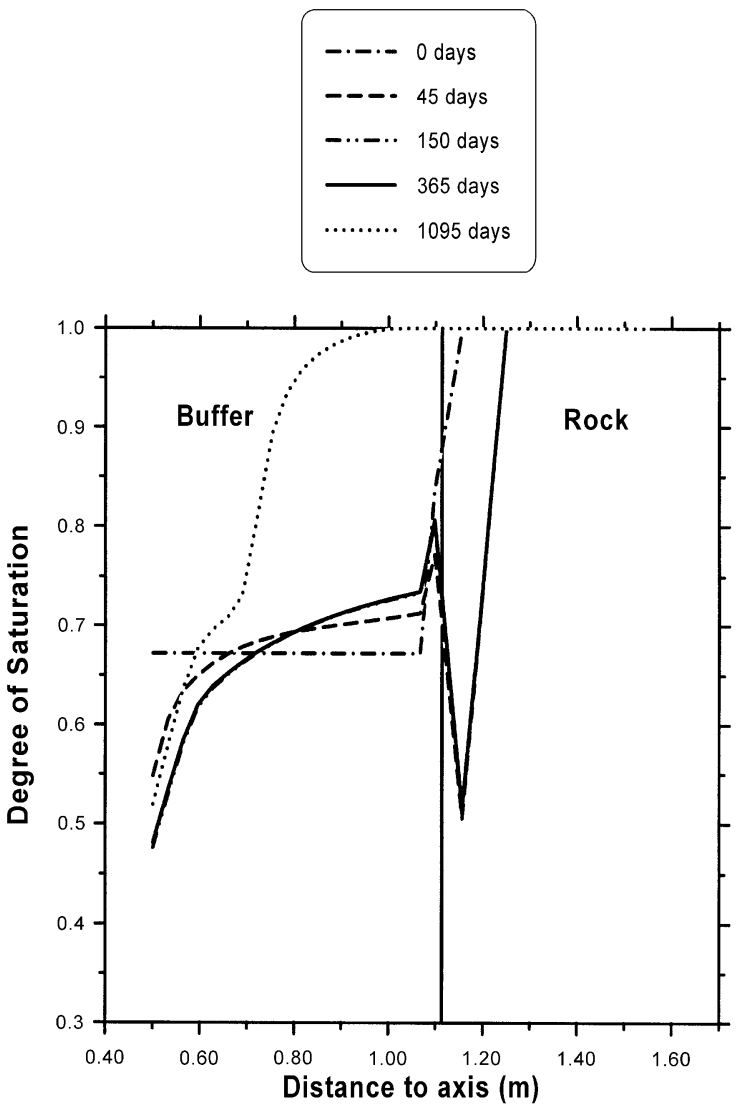

Fig. 11. Distribution of degree of saturation at various times. KB analysis (increased bentonite permeability).

exerts an important influence, especially on the state of the barrier close to the heater.

\subsection{Bentonite permeability}

The analysis, coded $\mathrm{KB}$, has been performed using an intrinsic permeability of $2 \times 10^{-20} \mathrm{~m}^{2}$, about three times higher than in the Base Case. The effect of this higher bentonite permeability is striking. As Fig. 11 shows, a strong desaturation of the granite occurs because the rock is unable to provide the increased inflow of water demanded by the larger hydraulic conductivity of the bentonite. At that point, a quasiimpermeable barrier is created that practically prevents the inflow of water into the buffer. As time goes on, the rock becomes saturated again and the progressive hydration of the buffer can then take place. This process can be clearly seen in Fig. 12 in which the 


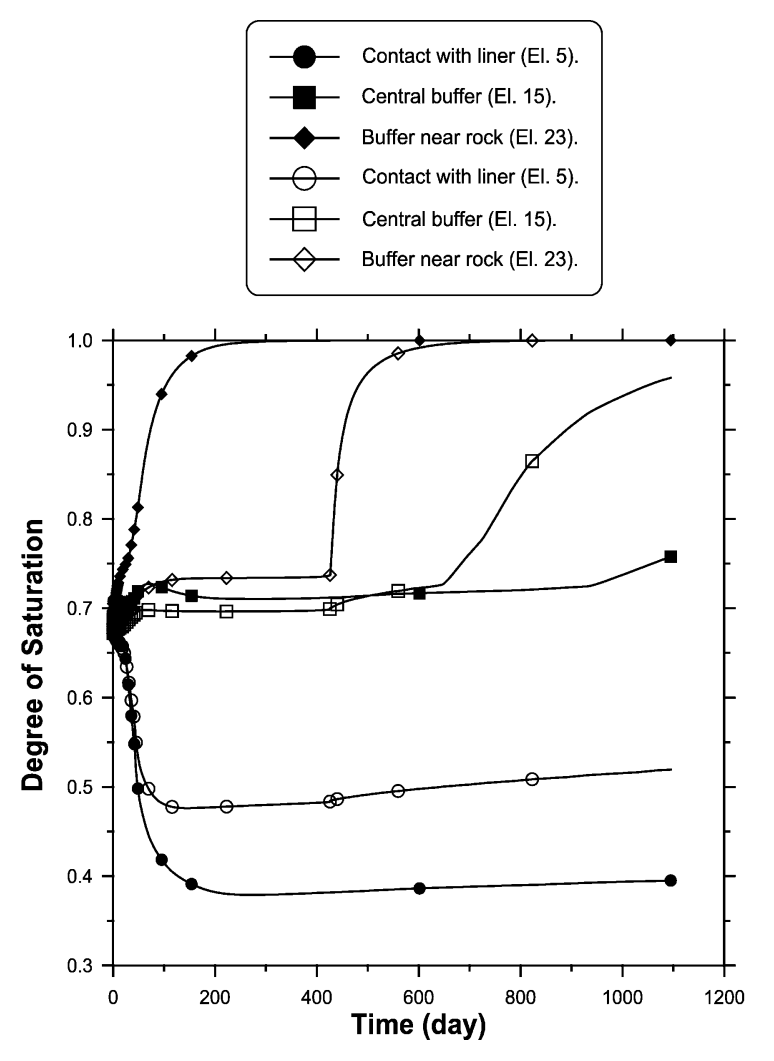

Fig. 12. Variation of degree of saturation with time. KB analysis (increased bentonite permeability). Black symbols correspond to Base Case.

hydration stoppage due to rock desaturation can be observed. Once resaturation of the granite is achieved, hydration takes place more quickly than in the Base Case because of the larger bentonite permeability.

In this context, it is interesting to examine the results of analysis KBPG in which the higher value of bentonite permeability has been used, but rock desaturation has been prevented by the use of a high air entry value in the retention curve of the granite. As Fig. 13 shows, no hydration delay is observed and the higher hydraulic conductivity of the bentonite results is a more hydrated barrier at the end of the analysis.

\subsection{Granite permeability}

The granite intrinsic permeability used in the Base Case, $8 \times 10^{-18} \mathrm{~m}^{2}$, was derived as an average value taking into account the rock mass as well as the discontinuities. Although the overall water entry value into test area is thus preserved, it is implicitly assumed that this inflow takes place in a uniform way, which clearly is not the case. There is a need, therefore, to carry out an alternative analysis (KG) in which the permeability corresponding more closely to the rock mass value $\left(10^{-18} \mathrm{~m}^{2}\right)$ is used. This case would then be more representative of a zone in which water inflow from large discontinuities is absent.

The distributions of degree of saturation obtained using this lower value of rock permeability are shown in Fig. 14. It can be noted that granite desaturation initially takes place because the rock is now unable to supply enough water to the bentonite. Eventually, however, the rock resaturates and hydration can then proceed (Fig. 15). At the end of the analysis, the final state of saturation of the barrier is only just below that of the Base Case. Performance of other parametric

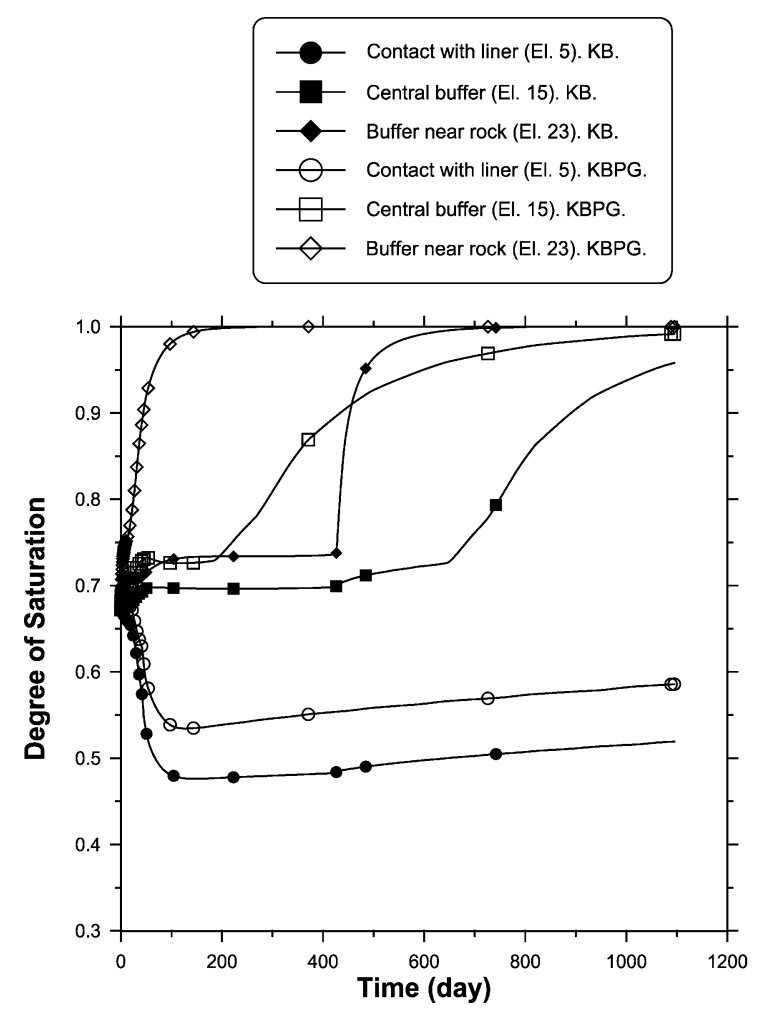

Fig. 13. Variation of degree of saturation with time. KB (granite desaturation) and KBPG (no granite desaturation) analyses. 

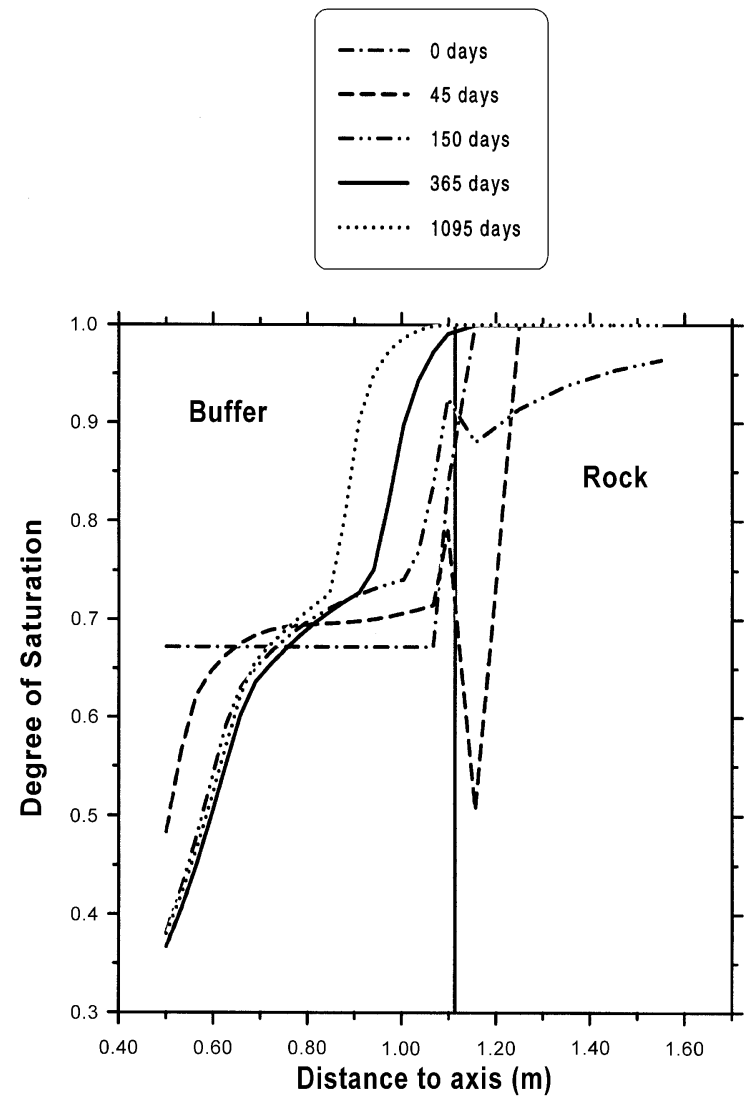

Fig. 14. Distributions of degree of saturation at various times. KG analysis (lower granite permeability).

analyses has demonstrated that the specific effect of rock permeability is, in this case, small.

\subsection{Retention curves of the granite and bentonite}

The intricacy of the interaction between buffer and host rock becomes strikingly apparent when examining the effect of the retention curve of the bentonite using only the dry branch of the basic relationship without considering any hysteresis effects, in contrast to the Base Case where retention curve hysteresis is incorporated in the analysis. The significance of a possible rock desaturation is clear in this case, analysis SH (Fig. 16). Now, desaturation of the granite occurs driven by the high suction values associated with the new retention curve. As the desaturation is maintained throughout the analysis, a very limited amount of hydration occurs, the average increase of the degree of saturation is only $4.1 \%$. Contrasting results are obtained in the equivalent analysis where no rock desaturation is allowed (PGSH). Now, not only hydration proceeds unimpeded, but full saturation of the buffer is achieved at the end of the analysis. The temperature field is also significantly changed due to the increased thermal conductivity associated with a more saturated barrier.

Therefore, the retention curve of the bentonite plays an important role in the analysis. The effects, however, are totally different depending on whether the rock desaturates or not. The potential importance of rock desaturation in many of the analyses involving hydraulic parameter variations calls into question the validity of averaging the hydraulic conditions occurring along the test site. An unavoidable consequence of these analyses is that very different hydration
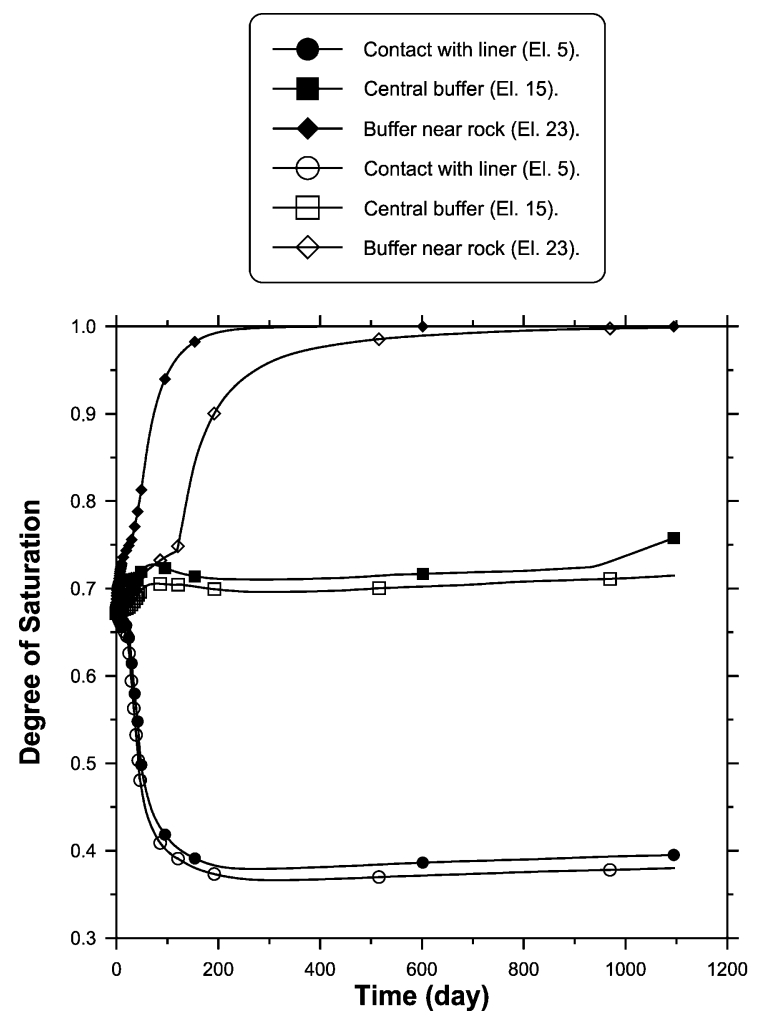

Fig. 15. Variation of degree of saturation with time. KG analysis (lower granite permeability). Black symbols correspond to Base Case. 


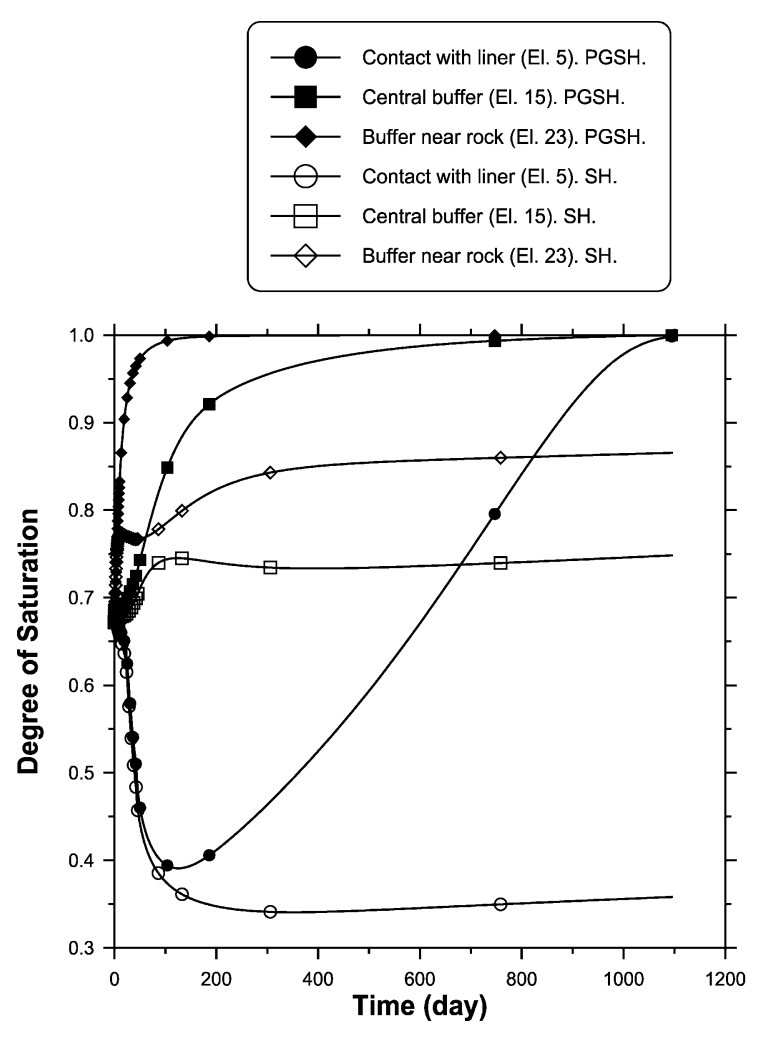

Fig. 16. Variation of degree of saturation with time. Analyses SH (granite desaturation) and PGSH (no granite desaturation).

regimes may coexist in different parts of the test. Their interplay in both rock and buffer gives the problem analysed a high degree of complexity.

\section{Conclusions}

The interaction between the engineered barrier and the host rock of a potential deep repository has been explored by means of a programme of parametric studies carried out in relation to a large-scale in situ heating test under way in the underground Grimsel Rock Laboratory. The study has revealed a high degree of complexity in the behaviour of the rock/ barrier system due to the coupled nature of the thermal, hydraulic, and mechanical phenomena that occur. It has been shown that vapour diffusion and hydraulic parameters have a very strong influence on the patterns of computed behaviour.
The high degree of complexity observed leads to apparently paradoxical results such as that a change of retention curve may accelerate or delay hydration depending on weather the rock can desaturate or not. Therefore, it is very risky to extrapolate effects observed with a set of parameters to another situation in which the materials may have quite different properties. For the same reason, special caution should be exercised when averaging material properties over a wide range of values, especially when dealing with the hydraulic aspects of the problem.

\section{Acknowledgements}

The support given by ENRESA to this work is gratefully acknowledged. Additional assistance has been given by the Ministry of Science and Technology through research grant BTE2001-2227.

\section{References}

Chapman, N.A., Mc Kinley, I.G., 1987. The Geological Disposal of Nuclear Waste. Wiley, Chichester.

ENRESA, 2000. Full-scale engineered barriers experiment for a deep geological repository for high -level waste in crystalline host rock. Technical Publication 01/2000. Enresa, Madrid.

Gens, A., 1995. Constitutive laws. Modern Issues in Nonsaturated Soils. Springer, Vienna, pp. 129-158.

Gens, A., García-Molina, A.J., Guimaraes, L. do N., Alonso, E.E., 1997. Preoperational thermo-hydro-mechanical (THM) modelling of the "in situ" test. 70-UPC-M-3-001. Universitat Politècnica de Catalunya, Barcelona.

Gens, A., García-Molina, A.J., Olivella, S., Alonso, E.E., Huertas, F., 1998. Analysis of a full-scale in situ test simulating repository conditions. Int. J. Numer. Anal. Methods Geomech. 22, $515-548$.

Olivella, S., Carrera, J., Gens, A., Alonso, E.E., 1994. Non-isothermal multiphase flow of brine and gas through saline media. Transp. Porous Media 15, 271-293.

Olivella, S., Gens, A., Carrera, J., Alonso, E.E., 1996. Numerical formulation for a simulator (CODE_BRIGHT) for the coupled analysis of saline media. Eng. Comput. 13, 87-112.

Panday, S., Corapcioglu, M.Y., 1989. Reservoir transport equations by compositional approach. Transp. Porous Media 4, 369-393.

Pintado, X., Lloret, A., 1996. THM laboratory tests in FEBEX phase I. Report 70-UPC-L-3-01. Universitat Politècnica de Catalunya, Barcelona.

Villar, M.V., Pelayo, M., 1996. Characterization of "La Serrata" clay used in the FEBEX project. Technical Report. 54A1411196. CIEMAT, Madrid. 